\title{
RELIABILITY IMPROVEMENT OF COOLING WATER PUMP
}

\author{
P. YOGESH ${ }^{1}$, R. RAGHAVAN ${ }^{2}$, R.VIGNESHKUMAR ${ }^{3}$, \\ R. HARISH ${ }^{4} \&$ K. PRAVEENKUMAR ${ }^{5}$ \\ ${ }^{I}$ Assistant Professor, Department of Mechanical Engineering, Vel Tech, Chennai, Tamil Nadu, India \\ ${ }^{2,3,4,5}$ Research Scholar, Department of Mechanical Engineering, Vel Tech, Chennai, Tamil Nadu, India
}

\begin{abstract}
The project presents an idea of analyzing the stress concentration occurring on the shaft. In the centrifugal pump, there are frequent failures of the shaft during operation, due to which it leads to a breakdown or stoppage of pump working and regular maintenance is conceived. In this project, to recognize the shaft failure, we calculate the load acting on the shaft and forces exerted by the impeller. The stress analysis of the shaft is done by ANSYS software and finally gives suggestions to improve the life of the shaft.
\end{abstract}

KEYWORDS: Centrifugal Pump, Impeller, Failure Mechanism, Fatigue Failure \& Torsional Failure

Received: Mar 13, 2018; Accepted: Apr 03, 2018; Published: May 31, 2018; Paper Id.: IJMPERDJUN201880

\section{INTRODUCTION}

The machines which change over the mechanical vitality into water powered vitality are called pumps. The water driven vitality is as weight vitality. On the off chance that the mechanical vitality is changed over into weight, vitality by methods for divergent power following up on the liquid, the water driven machine is called outward pump. The pump acts as a reversed of Associate in Nursing inward radial flow turbine. This implies that the flow in centrifugal pumps is within the radial outward directions. The pump works on the principle of forced vortex flow, which suggests that once an explicit mass of liquid is revolved by Associate in Nursing external torsion, the increment in weight leader of the turning fluid happens. The ascent in weight head at any reason for the pivoting fluid is corresponding to the sq. of the digressive rate of the fluid around them. Due to this the outlet of the blade wherever radius is a lot of, the increase in pressure head are a lot of and also the liquid is discharged at the outlet with an air mass head. Due to this air mass head of the liquid is upraised to a high level.

\section{Main Parts of a Centrifugal Pump}

The accompanying is the fundamental parts of a centrifugal pump, Impeller, Casing, Suction pipe with a foot valve and a strainer, Delivery pipe.

Impeller

Impellers are the rotating blades that truly move the fluid. They're connected to the drive shaft that rotates among the pump casing. The vane is mounted on a shaft that is regenerate to the shaft of an electrical motor. Impellers are classified in a number of different ways: Direction of flow relative to the axis of the shaft. Radial flow Axial flow, Mixed -flow 


\section{Type of Suction}

Single-suction (Liquid inlet on one side) Double-suction (Liquid inlet on both sides)

\section{Mechanical Construction}

Open: No covers or divider to encase the vanes Closed: Shrouds or sidewall encasing the vanes Semi-open or vortex write. The one that is within the diagram may be a semi-closed vane captioned as open kind. Open and semi-open impellers square measure less vulnerable to impending, however, need manual adjustment to the volute or back-plate to stop internal re-circulation. Closed impellers need wear rings, that should get replaced sporadically, presenting a maintenance downside. Vortex impellers square measure effective for solids and fibrous material show ever they 'reless economical than alternative styles.

\section{Stages of Pump}

The quantity of impellers decides the quantity of the phases of the pump. Single Stage pump has only one impeller and is better for low head benefit Two-Stage pump has two impellers mounted in the arrangement for a medium head benefit. A multi-Stage pump has at least three impellers mounted in the arrangement for high head administration, for example, in profound well pumps.

\section{Shaft Sleeve}

Shaft Sleeves extend on the far side of the outer face of the seal secreter plate and defend the shafts from erosion, corrosion, and wear. Leak between the shaft and therefore the sleeve is totally different from a leak through the mechanical seal.

\section{Coupling}

Shaft Couplings compensate for the axial growth of the shaft and transmit torque to the impeller. They may be either rigid or flexible. Rigid couplings are used when there is a chance of misalignment. Flexible couplings are more forgiving, and may be either elastomeric (using rubber or polymer parts) or non-elastomeric (using metallic parts).

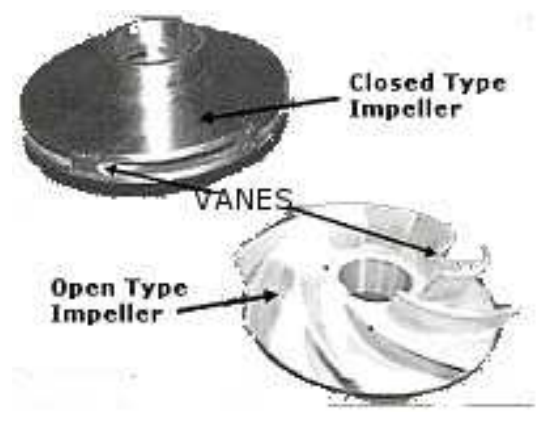

Figure 1: Coupling

\section{Seal Chamber/Stuffing Box}

A chamber, either integral with or separate from the pump case housing that forms the region between the shaft and casing where sealing media are installed for the primary function is achieved by means of a mechanical seal, the chamber is commonly referred to as a Seal Chamber. When the sealing is achieved by means of protecting the pump against leakage. When the sealing of a packing, the chamber is referred to as a Stuffing Box. 


\section{Strainer}

A gadget introduced in the bay of a pump to keep outside particles from harming the inner parts.

\section{Bearings}

The bearing lodging encases the course that keeps the pole in remedy arrangement with the stationary parts. It likewise incorporates an oil supply for oil, oiler, and cooling coat.

\section{Auxiliary Components}

Auxiliary components generally include seal drains, vents, and cooling systems, bearing lubrication, seal chamber or stuffing box cooling, and pump pedestal cooling systems. Auxiliary piping systems may include tubing, piping, various types of valves and gauges, thermocouples, sight flow indicators, fluid reservoirs, and all related vents and drains.

\section{Pump Details}

$\begin{array}{ll}\text { Weight of the shaft } & =147 \mathrm{~kg} . \\ \text { Weight of the Impeller } & =256 \mathrm{~kg} . \\ \text { Width of impeller } & =105 \mathrm{~mm} . \\ \text { Inner diameter of Impeller } & =530 \mathrm{~mm} \\ \text { Outer diameter of Impeller } & =640 \mathrm{~mm} . \\ \text { Weight of Impeller } & =256 \mathrm{~kg} . \\ \text { Speed of the Impeller } & =1000 \mathrm{rpm} . \\ \text { Material of Impeller } & =\text { cast steel. } \\ \text { Material of shaft } & =\text { EN8 } \\ \text { Material of Key } & =\text { Mild steel. }\end{array}$

\section{Single Stage Double Suction Centrifugal Pump}

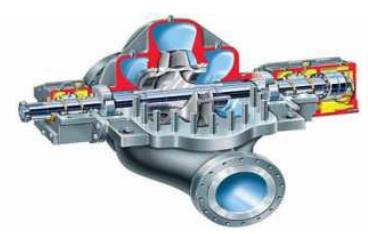

Figure 2: Single Stage Double Suction Centrifugal Pump

\section{CHAPTER-3}

\section{WP-2}

\section{Background}

In $51 \mathrm{WP}-2$, the water which is collected in the sump from the cooling tower is allowed to flow via the suction pipe to the water pump under atmospheric condition. The water pump which is powered by an induction motor rated with BHP-1250, Voltage-6600 volts, Current-100 amps, and Speed-1000 rpm allows the pump shaft to rotate. The impeller which is a double suction single delivery has seven backward curved vanes is mounted on the shaft. The motor initiates the 
rotation of the shaft, due to the which the impeller starts rotating, due to rotation the water enters the impeller radially at eye inlet which is then allowed to flow inwards in two suction head and delivers at the delivery head. The mechanical vitality is changed over into weight, vitality by methods for diffusive power following up on fluid.

\section{Visual Inspection Observation}

A failure occurred at the end (right side) of lock nut towards Non - Driven end. The failure appeared is fatigue fracture.

\section{DISCUSSIONS}

From closer visual inspection of the shaft breakdown, certain pits were found on the shaft surfaces which indicate corrosion activities on the shaft. The accumulation of corrosion product can be clearly seen in the sheared area. This corrosion initiated in sheared area due to non-availability of the productive film due to shearing. The material of the shaft 51WP-2 is En-8 (C45) used as per design standard. The fracture shows typical fatigue failure.

\section{Failure Mechanism}

From the analysis (ANSYS) software, it has been found that stress has started from the middle of the shaft (impeller position) and raises both sides of the impeller. The stresses are maximum on the shaft where (as shown in red color in ansys) but the breakage has been taken place at the lock nut (right side end) of non driven end. The thrust bearing was inspected visually and no defects have been found. So, the main causes of the shaft failure are:-

\section{Misalignment of Mountings on the Shaft}

The misalignment of mountings on the driven end has imposed more stress at the non-driven end. In the driven end, we have lots of protection in comparison to the non driven end. As the lock nut towards the non-driven end is the position where more stress concentration factor has been taken place. So the shaft failure has occurred on the edge of the lock nut.

\section{Corrosion Occurring at Juncture of Both Lock Nut and Shaft}

The failure mechanism due to corrosion at the juncture of both lock nut and shaft could be divided into 3 steps: Crack initiation, Crack propagation. Shaft sheared.

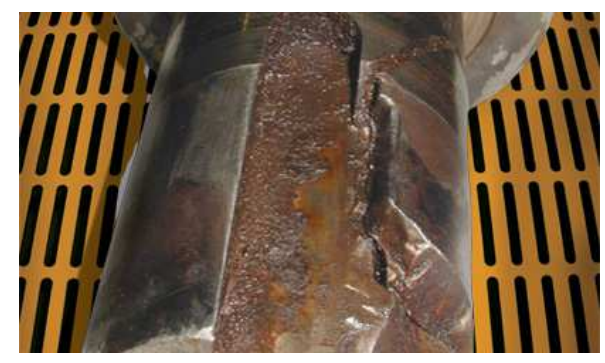

Figure 3: Failure Analysis of Machine Shafts

As the industrial arena grows a lot of refined, it appears like operations area unit endeavor fewer and fewer broken machine shafts. Once shafts DO break, however, there is a area unit nearly always as several theories concerning the suspected culprits as there area unit individuals concerned. 


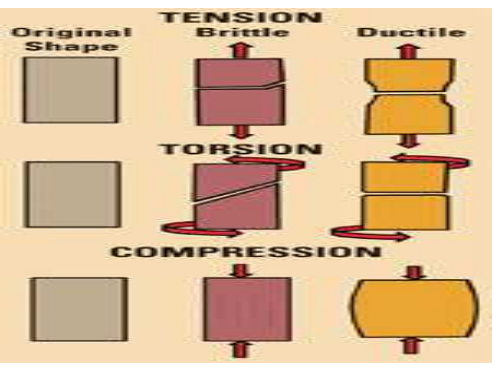

Figure 4: The Presence of an Over-Burden Disappointment Relies Upon whether the Pole Material is Fragile or Ductile

Whether related to engines, pumps or alternate sorts of mechanical apparatus, shaft disappointment examination is usually misjudged, generally saw as troublesome and significant. for some, machine shafts, be that as it may, the examination should be nearly simple. That is because of the disappointment more often than not gives solid insights to the kind and greatness of powers on the pole and in this manner the course they acted in: The falling flat components can tell correctly what happened. There square measure solely four basic failure mechanisms: corrosion, wear, overload and fatigue. the primary two-corrosion and wear-almost neer cause machine-shaft failures and, on the rare occasions they are doing, leave clear proof. Of the opposite 2 mechanisms, fatigue is additional common than overload failure. (NOTE: bind mind that few times erosion can act in conjunction with exhaustion stacking to cause a pole disappointment.) this content can represent considerable authority in disappointments resulting from over-burden and weakness factors.

\section{Overload Failures}

Over-burden disappointments are caused by the powers that surpass the yield quality or the elasticity of a material. As delineated in Figure 1, the presence of an over-burden disappointment relies upon whether the pole material is weak or flexible.

No pole materials are completely fragile or totally flexible. The poles utilized on all engines, reducers and fans are low-or medium-carbon steels and generally flexible. Thus, when an extraordinary over-burden is set on these materials, they bend and twist. The twisted shaft appeared in Photo 1 has been terribly over-burden by a torsional push.

Vital Note: When Was the Failure Force Applied? n assignment that system caused the disappointment, a junction to remember is that over-burden disappointments square measure more often than not caused by one load application, though exhaustion disappointments square measure ceaselessly the consequences of a heap connected more than once more than a few cycles. This recommends if the pole flopping as a consequence of partner over-burden, the power that caused the disappointment was connected the minute prior to the pole stone-broke. On the other hand, if exhaustion was the transgressor, the underlying power could are connected to voluminous cycles previously a definitive disappointment happened. There square measure occasional cases, once a ductile shaft can fail during a somewhat brittle manner. Figure half dozen shows associate example of this situation-i.e., what happened once a two hundred power unit, 3600 rev motor suddenly stopped running. The result was an enormous torsional stress and a cracked shaft. however as a result of the fabric is ductile, the angle of the crack it's not at the $45^{\circ}$ position shown in Figure 5 , and there's obvious distortion of the keyway. Once ductile materials square measure grossly overladen terribly speedily, they have a tendency to act during a brittle manner. 


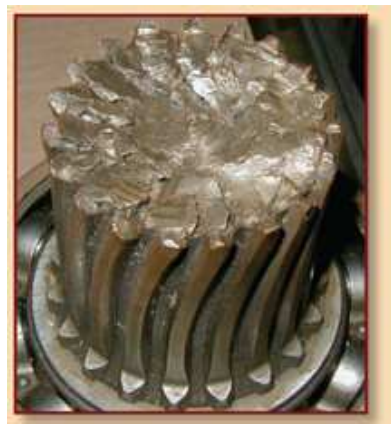

Figure 5: This Shaft has been Grossly Overloaded by a

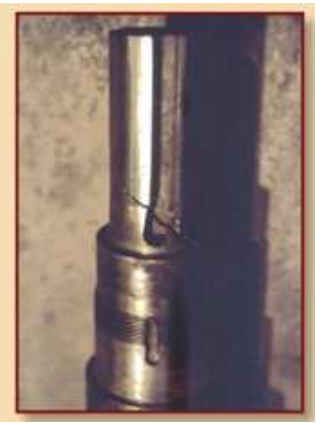

Figure 6: Occasionally, a Ductile Shaft will fail in a somewhat

Luckily, fragile cracks of machine shafts are to a great degree uncommon. Like every single weak break, they are described by a generally uniform surface harshness - the split goes at a steady rate, and surface highlights called "chevron marks" are obvious. Photograph 3 demonstrates the fragile crack of the information shaft of a larger than average reducer that was conceived. The "chevron marks" are the fine ripples on the surface that all points just to the left of the keyway. Occasionally, a little of a machine shaft are hard to cut back the wear and tear rate. (NOTE: Case-hardening is usually done solely for wear-resistance purposes.) Photo 4 shows the hard-boiled splined section of a hydraulic ram shaft, as well as its hardened case, the ring rounds the circumference with a awfully totally different texture than the bulk of the shaft and "chevron marks" that time to the origin of the harm. Supported however, this break developed straight over the pole, the reason may are related with either bowing or pressure. Its nearly uniform surface, however, would show that this crack is of a weak sort-which moreover recommends that it had been caused by one power application. in addition, since it's unrealistic to put indispensable pressure on a spline, the investigator may securely say that one twisting power caused the disappointment.

\section{FATIGUE FAILURES}

Fatigue is caused by alternate stresses, and therefore the forces that cause fatigue failures square measure well but those who would cause plastic deformation. Confusing things even more, is that the proven fact that corrosion can cut back the fatigue strength of a fabric. the \{number\} of reduction relies on each the severity of the corrosion and therefore the number of stress cycles. Once they're visible to the eye, cracks forever grow perpendicular to the plane of most stress. Figure seven shows the fracture planes caused by four common fatigue forces. as a result of the section, properties can modification because the crack grows, it's crucial for the analyst to seem rigorously at the purpose wherever the failure starts to work out the direction of the forces. as an example, whereas it's common for torsional fatigue forces to initiate a failure, the bulk of the crack propagation may be in tension. That's as a result of the shaft has been weakened and therefore the torsional resonant frequency has modified. Prompted breaks, in any case, traverse the crack face at regularly expanding speeds. Thus, the regular pressure crack face is \{comparatively\} wash near the origin(s) and closures in an exceedingly similarly harsh last break. 


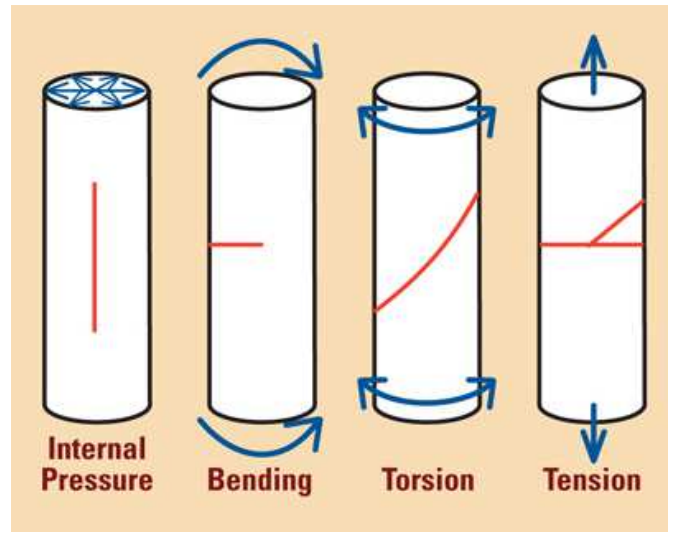

Figure 7: Fracture Planes caused by Four Common Fatigue Forces: Because the Section Properties will change as the Crack Grows, it'd Important to Look

Carefully at the Point where the Failure Starts to Determine the Direction of the Forces

The condition or harshness of the crack surface is a standout amongst the most critical focuses to take a gander at in breaking down a disappointment on account of the distinction between over-burden disappointments and weariness disappointments. With over-burden disappointments - in light of the fact that the break goes at a steady rate-the surface is consistently unpleasant. Weakness A common plain twisting exhaustion disappointment is delineated in Figure 8. The split began at the starting point and gradually developed over the Fatigue Zone (FZ). When it achieved the limit of the Instantaneous Zone (IZ) the break development rate expanded colossally and the split traversed the IZ at around 8000 $\mathrm{ft} / \mathrm{sec}$. Amid the time of development over the FZ, there might be changes in the stacking on the pole, which result in changes in the surface that show up as movement marks.

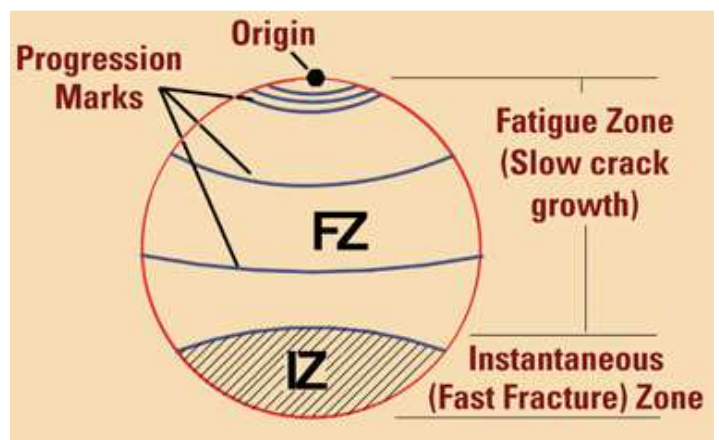

Figure 8: This Typical Plane Bending Fatigue Failure Shows How a Crack

Starts at the Origin and Grows across the Fatigue Zone, When the

Crack Reaches the Boundary of the Instantaneous Zone, its Growth Rate Increase Significantly

\section{Rotational Loads or Plane Bending}

For a weakness inability to happen, the powers more likely than not been connected ordinarily. There are lowcycle disappointments yet most modern weakness disappointments we've seen include in excess of 1,000,000 load cycles. A profitable element of exhaustion disappointment understanding is that the breakable development, i.e., the surface appearance, tells how the heap was connected. In the event that the split develops straight over the pole (as appeared in Figure 3), the power that caused the disappointment more likely than not been a bowing burden working in a solitary plane. 
Figures 9 and 10, be that as it may, indicate cases of pivoting twisting. The contrast between these two disappointments is that the pole in Figure 4 has a solitary birthplace, while the crack in Figure 5 has various causes. Taking a gander at the two portrayals, we see the IZ of Figure 4 is the bigger of the two-which demonstrates that the heap on the pole when it fizzled was more prominent than that on Figure 5. The investigation, likewise demonstrates that, despite the fact that Figure 5 was less intensely stacked, it had numerous more crack starting points, a sign of a high-pressure focus, for example, a pole advance with a little span. The ratchet marks are the planes between contiguous break roots and develop opposite to the split engendering.

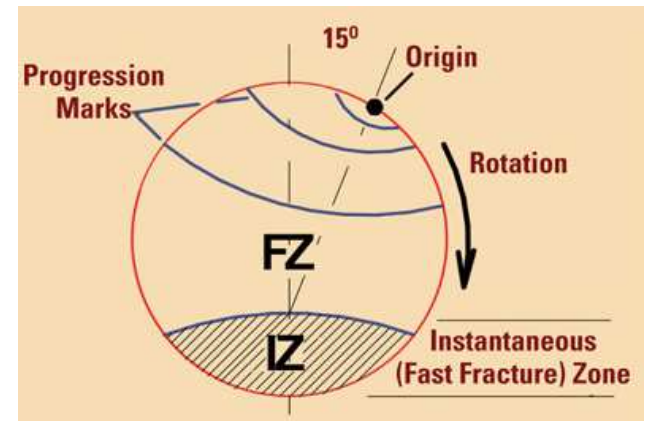

Figure 9: In this Example of Rotating Bending Failure, the Fracture has a Single Origin (and the Load on the Shaft when it Failed was Greater than that on Shaft in Figure10 when it Failed)

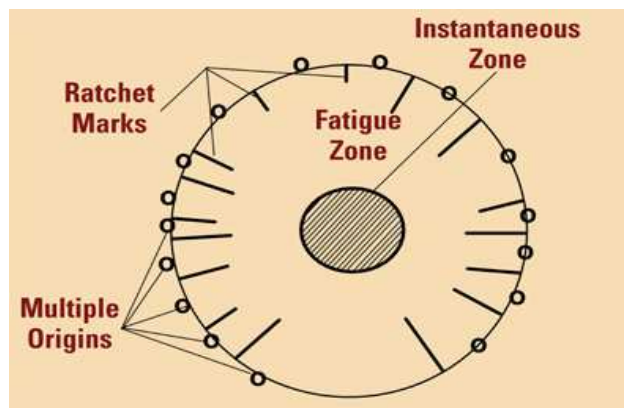

Figure 10: Analysis of this Rotating-Bending Failure (with its Multiple Fracture Origins) Showed that the Shaft was Less Heavily

Loaded than that in Figure 9 when it Failed

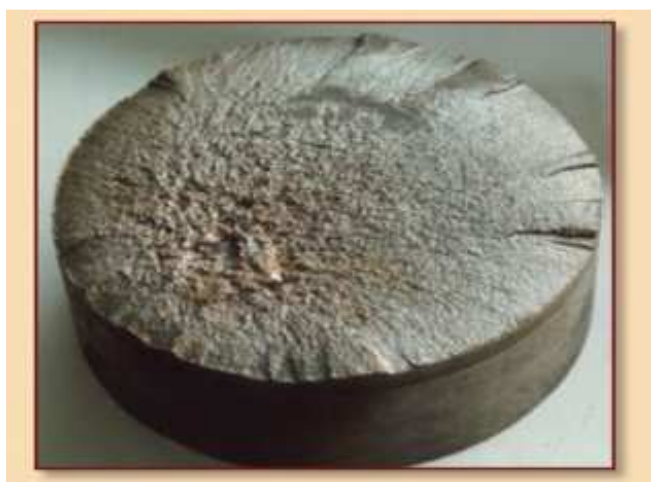

Figure 11: The Shaft on this 200hp, 1180 RPM Motor Failed in Less than a Day as a Result of Badly Worn Sheaves on the Belt Drive 


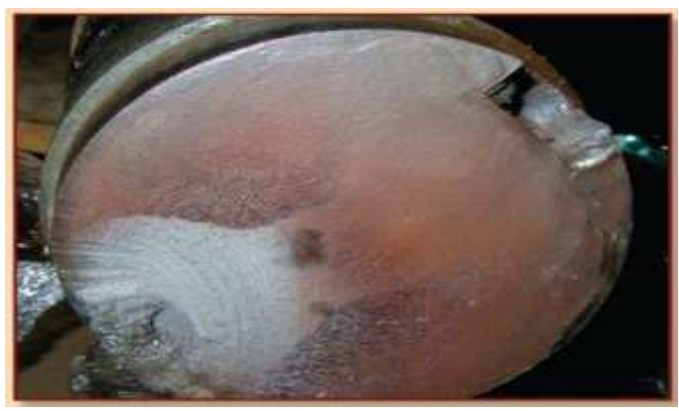

\section{Figure 12: This Slow-Growing Failure on a Steel-Mill Elevator Dive was Initiated by Fretting Corrosion that Substantially Reduced the Failure Strength on the Shaft}

A few cases of plane and pivoting twisting weakness determination is appeared in Photos 11 and 12. Photo 11 demonstrates a $200 \mathrm{hp}, 1180$ RPM engine shaft that bombed in under a day. No movement marks implies the weakness stack was steady. The momentary zone is generally huge, demonstrating the pole was intensely stacked. Splitting began at various areas around the pole, indicating pivoting twisting as the reason. Such huge numbers of ratchet marks focused on the best and base of the photograph make us speculate the pole might not have been straight. Assessment, however, would demonstrate the main driver was related with the belt drive. Truth be told, the piles were worn so severely that the belts were riding in the base of the depressions. This circumstance around, multiplied the pole twisting stress. The drive shaft in Photo 12 was on a steel-process lift. The surface is smoothest close to the base of the keyway and turned out to be dynamically rougher as the break developed over the pole. Various movement marks encompassing the modest IZ and the adjustment in surface condition around $40 \%$ of the path over the pole from the IZ recommend something changed amid the split development or that the lift was not utilized for an expanded period. These highlights are demonstrative of a moderate developing disappointment—and the way that fussing erosion may have generously diminished the exhaustion quality.

Torsional exhaustion disappointments... Until the appearance of variable speed drives (VSDs), torsional weakness disappointments were uncommon: Equipment creators could foresee working rates and excitation frequencies and specialist around them. The reason for a VSD is to permit activity at an extensive variety of rates. That, tragically, has prompted numerous engine and driven-shaft disappointments due to torsional-weariness factors. While the most widely recognized torsional weakness splits begin at the sharp corner (push fixation) at the base of the keyway when the couplings are ineffectively fitted, another basic appearance is the askew shaft break (like that appeared in Figure 2). Photograph 13 mirrors the battered end of an engine shaft with an unpleasant (free) coupling fit that let the center point over and again drive the key against the side of the keyway until the point that a weakness split created. (It's normal to see situations where the split has spread totally around the pole, leaving just a stub on the pole.)

Photograph 14 indicates the two parts of the torsional-exhaustion disappointment of a fan shaft in a plant that had as of late changed to a VSD. The $45^{\circ}$ edge to the focal pivot is a certain indication of torsional stresses, and the adjustment in surface unpleasantness over the pole demonstrates the reason was weakness powers. 


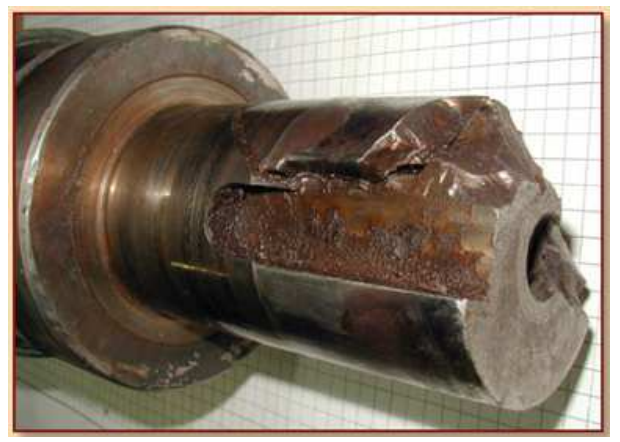

Figure 13: The Terrible (Loose) Coupling Fit on tis Motor Shaft Allowed the Hub to Repeatedly Dive the Key against the Side of the Keyway until a Fatigue Developed

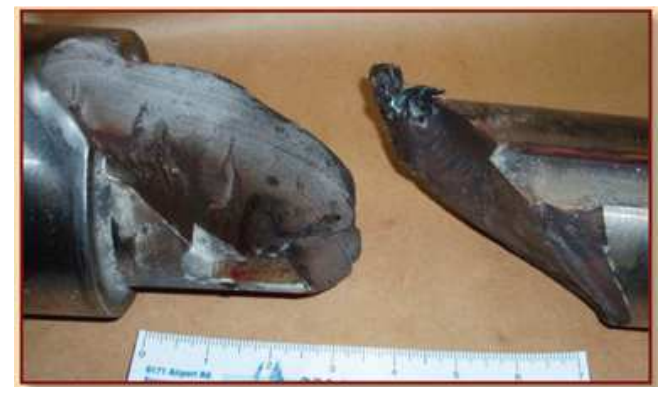

Figure 14: The Torsional Fatigue Failure of this Fan Shaft Occurred Shortly after the Installation of a Variable Speed drive

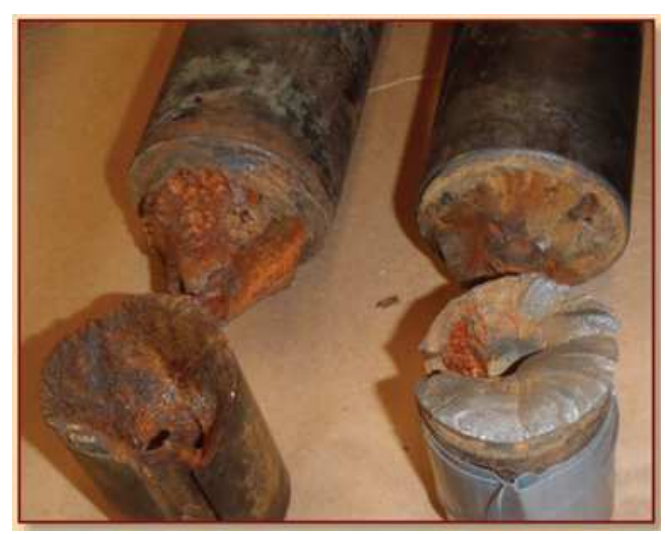

Figure 15: These Pump Shafts Failed due to Torsional Fatigue Aggravated by the Reduction in Strength caused by Corrosion, not because of Rotating Bending

\section{PROGRAMMING OF ENGINEERING DIAGRAM}

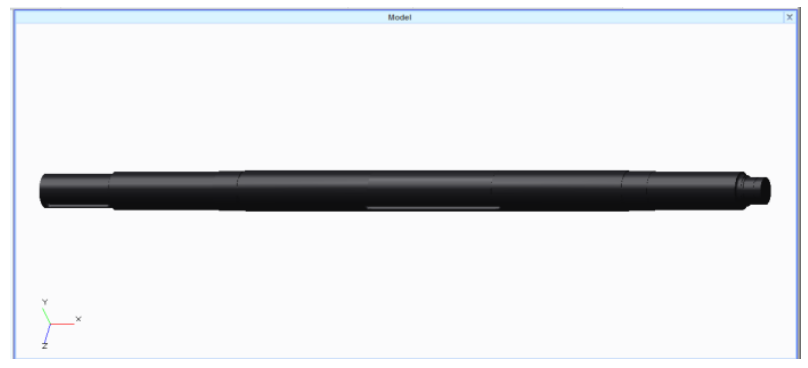

Figure 16: Fillet 


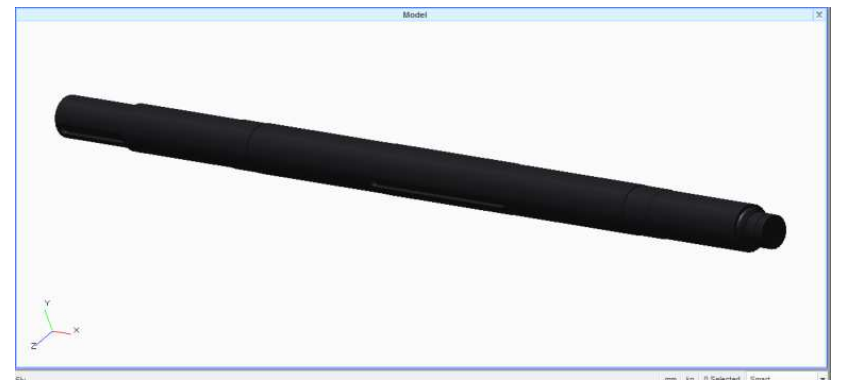

Figure 17: Without Fillet

\section{CONCLUSIONS}

The combined action of environment, geometry and fatigue stresses might be causes for the crack initiation. The final stage of shaft failure is resulted by mechanical stresses.

\section{RECOMMENDATIONS}

Care to be taken to check the misalignment of mounting the shaft. Preferred corrosive coating materials (zinc, chromium) should be used for protecting the shaft from atmospheric environmental conditions.

Possibility of others stress reduction method is to be explored in future.

\section{REFERENCES}

1. "Centrifugal pumps - Basic concepts of operation, Maintence\& Troubleshooting" by Mr. MukeshSahdev, The chemical Engineers

2. "The role of centrifugal pump in water supply" Dr. Bassam .A .Al-Helou, Faculty of engineering, Jordon, Journal of Applied science No.406-410, 2004.

3. Harada H, performance characteristics of shrouded and un shrouded impellar ofa centrifugal compressor, ASME journal of engineering for gas Turbines and power, vol.107,pp.528-533,(1985)

4. XianwuLuo, YaoZhang, jungipeng,et al.:Impellar inlet Geometry Effecton Performance Improvement For Centrifugal Pumps,Journal ofMechanical science and Technology,vol.22,pp.1971-1976(2008).

5. Young-Do Choi, Junichikurokawa, JunMatsui: performance and Internal Flow Characteristics of a Very Low Specific Centrifugal Pump, Journal of fluids Engineering,vol.128,pp.341-349(2006)

6. Cui Baoling, ZhaoRui, ZhangYuliang, etal.: The Research on Flow Characteristics of High Speed Pump with Open Impellar 
